\title{
The Comparison of Perinatal Outcomes in Early Delivery Versus Postdate Labor
}

\author{
Maryam Khooshideh, ${ }^{1}$ Shahin Nariman, ${ }^{2}$ Saeid Safari, ${ }^{3}$ and Ali Shahriari ${ }^{4,}$ \\ ${ }^{1}$ Department of Obstetrics and Gynecology, Arash Hospital, Tehran University of Medical Sciences, Tehran, IR Iran \\ ${ }^{2}$ Department of Pediathrics, Arash Hospital, Tehran University of Medical Sciences, Tehran, IR Iran \\ ${ }^{3}$ Pain Research Center, Iran University of Medical Sciences, Tehran, IR Iran \\ ${ }^{4}$ Departement of Anesthesiology, Razi Hospital, Tehran University of Medical Sciences, Tehran, IR Iran \\ "Corresponding author: Ali Shahriari, Departement of Anesthesiology, Razi Hospital, Tehran University of Medical Sciences, Tehran, IR Iran. Fax: +98-2177880909, E-mail: \\ ashahriari@tums.ac.ir
}

Received 2017 January 16; Revised 2017 January 29; Accepted 2017 February 03.

\begin{abstract}
Background: Prenatal mortality and morbidity increase after 40 weeks of gestation. The current study aimed at comparing maternal and neonatal outcomes between term and postterm pregnancies.

Methods: The current prospective cohort study was performed on 1180 singleton, cephalic fetus, and uncomplicated pregnancy cases admitted for labor. Pregnant mothers were divided into 3 groups. Group 1 included 750 cases in 38 to 40 weeks, group 2 included 250 cases in 40 to 41 weeks, and group 3 included 180 cases in over 41 weeks of gestation. Prenatal outcomes were recorded as: fetal distress, meconium passage, meconium aspiration, fetal weight $\geq 4 \mathrm{~kg}$, Apgar score in 1 and 5 minutes, neonatal intensive care unit (NICU) admission, maternal infection, postpartum hemorrhage, and the rate of cesarean section.

Results: There were significant differences in the rate of fetal distress $(\mathrm{P}<0.001)$, meconium passage $(\mathrm{P}=0.001)$, meconium aspiration syndrome $(\mathrm{P}<0.001)$, Apgar score $\leq 3$ at $1(\mathrm{P}=0.025)$ and 5 minutes $(\mathrm{P}<0.001)$, admission to $\mathrm{NICU}(\mathrm{P}<0.001)$, rate of cesarean section $(\mathrm{P}<0.001)$, and maternal infection $(\mathrm{P}=0.001)$ among the groups. The frequency of fetal distress was lower in group1 compared with group $2(1.6 \%$ versus $4.4 \% ; \mathrm{P}=0.011)$. Also fetal distress was significantly lower in group 1 than group $3(1.6 \%$ versus $10.9 \%$; $\mathrm{P}<0.001)$. The meconium passage and meconium aspiration syndrome were statistically lower in group 1 compared with group 2 (1.6\% versus $8 \% ; \mathrm{P}<0.001$ for meconium passage, and $0.9 \%$ versus $5.6 \% ; \mathrm{P}<0.001$ for meconium aspiration syndrome). Also meconium passage and meconium aspiration syndrome were significantly lower in group 1 compared with group 3 (1.6\% versus $13.9 \%$; $\mathrm{P}<0.001$ for meconium passage, and $0.9 \%$ versus $10 \% ; \mathrm{P}<0.001$ for meconium aspiration syndrome). The cesarean section was more frequent in group 2 compared with group 1 (24.8\% versus $13.6 \% ; \mathrm{P}<0.001$ ) and in group 3 compared with group 1 (33.3\% versus $13.6 \%, \mathrm{P}<0.001$ ). There was no significant difference in the mean fetal weight, fetal weight $\geq 4 \mathrm{~kg}$, and postpartum hemorrhage in females between the 3 groups.
\end{abstract}

Conclusions: Late-term and postterm births are associated with higher rates of fetal and neonatal morbidity and maternal risks compared to pregnancy termination before 40 weeks of gestation, and earlier birth induction is recommended in such cases.

Keywords: Pregnancy Complications, Postdate Pregnancy, Term Pregnancy, Prenatal Complications

\section{Introduction}

The mean duration of a normal pregnancy is 40 weeks of gestation. Based on the World health organization (WHO) definitions, postdate delivery lasting 42 weeks or more is referred to postterm, and the pregnancies between 40 and $41+6$ weeks as late-term deliveries (1). Full term pregnancy is defined by the American Congress of Obstetricians and Gynecologists as 39 to 40 weeks of gestation $(2,3)$.

More than $40 \%$ of all pregnant mothers give birth after 40 weeks (1). The pregnant population $>41$ weeks constitutes $15 \%-20 \%$ of all pregnancies (4) and postterm birth rates is observed in a range of $0.4 \%$ to $8.1 \%$ (5). Postdate deliveries are associated with fetal, neonatal, and maternal risks $(6,7)$.
Fetal and neonatal complications of postterm and lateterm pregnancies are macrosomia, fetal dysmaturity, increased risk of umbilical cord compression due to oligohydramnios, abnormal antepartum or intrapartum fetal heart rate patterns due to placental insufficiency or cord compression, meconium passage and aspiration, and prenatal deaths (6-8). The long-term effects of postterm birth are unclear, but may include neurologic risks such as epilepsy and cerebral palsy $(9,10)$.

Maternal risks of postterm pregnancy include an increased frequency of failed induction, 3rd and 4rd degree perinea lacerations, infection, and postpartum hemorrhage (9-12). Management of pregnant mothers with no onset of labor ranges from expectant management consisting of intensive monitoring of mother and fetus to in- 
duction of labor (1). The American College of Obstetricians and Gynecologists recommends induction of labor after 42 weeks of gestation, but considers induction at 41 to 42 weeks reasonable (13).

Most of the obstetricians prefer expectant management with monitor fetal well-being, twice weekly in 40 to 41weeks and they choose induction of pregnancies at 41weeks of gestation to reduce prenatal mortality and morbidity. They suggest that induction of labor at 40 to 41weeks in uncomplicated pregnancy has overall similar outcomes compared with expectant management and termination of the pregnancy, which is indicated when results of the recent examinations indicate a risk for mother or child. They believe that this is a reasonable approach, because of the low absolute rate of fetal death in late-term and the relatively high number of inductions that would be required to prevent one prenatal death (14-18).

In contrast, prenatal mortality and morbidity increase with increasing gestational age after 40 weeks (5). For mothers at 40 weeks of gestation, some obstetricians suggest induction rather than expectant management to reduce prenatal mortality and morbidity or cesarean delivery rates $(14,17,19)$.

The current study compared neonatal and maternal complications in mothers with 38 to 40,40 to 41 , and $>41$ weeks of gestation.

\section{Methods}

After approval by the ethics committee, the current prospective, cohort study was performed on1180 singleton and uncomplicated pregnant mothers admitted for labor in Arash hospital in Tehran, Iran, from 2014 to 2015. Mothers with singleton, cephalic, and low risk pregnancies $\geq 38$ weeks of gestation were included.

Females with underlying diseases, drug users, previous cesarean delivery, and fetus with anomaly in ultrasound, multiple gestations, non-cephalic presentations, and complicated pregnancies were excluded.

Pregnant mothers were divided into 3 groups: Group 1 included 750 cases in 38 to 40 weeks, group 2 included 250 cases in 40 to 41 weeks, and group 3 included 180 cases in more than 41 weeks of gestation. Pregnant females were observed for vital signs, progress of labor, and electronic monitoring of fetal heart rate. Mode of delivery, fetal weight, Apgar score in 1 and 5 minutes, fetal distress, meconium passage, meconium aspiration in fetus, neonatal intensive care unit (NICU) admission, maternal infection, and postpartum hemorrhage were recorded as outcomes of the study.

\subsection{Data Analysis}

All data analyses were conducted using SPSS version 21.0 for Windows (SPSS Inc., Chicago, IL, USA). Descriptive statistics for continuous variables were presented as mean \pm standard deviation (SD) and for categorical variables as numbers (percentage). The baseline characteristics, primary and secondary outcomes of the 3 groups were compared using one-way ANOVA test (followed by Scheffe post hoc test) for continuous variables and the Chi-square test for categorical variables. All statistical tests were 2-sided and the level of statistical significance was 0.05 .

\section{Results}

Baseline and demographic characteristics are shown in Table 1. There was significant statistical differences in the rate of fetal distress $(\mathrm{P}<0.001)$, meconium passage ( $\mathrm{P}$ $=0.001)$, meconium aspiration syndrome $(\mathrm{P}<0.001)$, Apgar score $\leq 3$ in new born at $1(P=0.025)$ and 5 minutes $(P$ $<0.001)$, and required NICU admission $(\mathrm{P}<0.001)$ among the 3 groups (Table 1 ).

Also, there were significant differences among the 3 groups in the rate of cesarean section $(\mathrm{P}<0.001)$ and maternal infection $(\mathrm{P}=0.001)$ (Table 1$)$. There were no significant difference in the fetal weight $\geq 4 \mathrm{~kg}$ and postpartum hemorrhage among females (Table 1).

Results were also compared between group 1 and group 2 (Table 2 ).

The frequency of fetal distress was lower in group 1 compared with group $2(1.6 \%$ versus $4.4 \% ; \mathrm{P}=0.011)$. The meconium passage and meconium aspiration syndrome were statistically lower in group 1 as compared with group 2 (1.6\% versus $8 \%$; $\mathrm{P}<0.001$ for meconium passage, and $0.9 \%$ versus 5.6\%; $\mathrm{P}<0.001$ for meconium aspiration syndrome).

The rate of cesarean section was more frequent in group 2 compared with group 1 (24.8\% versus $13.6 \%$; $\mathrm{P}<$ 0.001).

Results were also compared between group 1 and group 3 (Table 3 ).

The rate of fetal distress was significantly lower in group 1 than group 3 (1.6\% versus $10.9 \%$; $>0.001$ ).

Also meconium passage and meconium aspiration syndrome were significantly lower in group 1 than group 3(1.6\% versus 13.9\%; $\mathrm{P}<0.001$ for meconium passage, and $0.9 \%$ versus $10 \%$; $\mathrm{P}<0.001$ for meconium aspiration syndrome).

The rate of cesarean section was significantly higher in group 3 compared with group 1 (5.6\% versus $10 \%$; $\mathrm{P}<0.001$ ).

The rate of fetal distress (4.4\% versus $10.6 \%$; $\mathrm{P}=0.013$ ) and meconium passage (33.3\% versus $13.6 \%$; $\mathrm{P}<0.001$ ) were significantly higher in group 3 compared with group 2 . 
Table 1. Baseline and Demographic Characteristics in the Study Groups ${ }^{a}$

\begin{tabular}{|c|c|c|c|c|}
\hline & 38 - 40 Weeks of Gestation $(n=750)$ & $40-41$ Weeks of Gestation $(n=250)$ & Above 41 Weeks of Gestation $(n=180)$ & P Value \\
\hline Age, $y$ & $27.06 \pm 5.73$ & $27.50 \pm 5.34$ & $27.41 \pm 5.39$ & 0.487 \\
\hline Birth weight, $\mathrm{g}$ & $3398.13 \pm 619.84$ & $3433.00 \pm 542.88$ & $3421.11 \pm 554.63$ & 0.693 \\
\hline Parity & & & & 0.123 \\
\hline 1 & $382(50.9)$ & $128(51.2)$ & $92(51.1)$ & \\
\hline$\geq 2$ & $368(49.1)$ & $122(48.8)$ & $88(48.9)$ & \\
\hline Birth weight $\geq 4000 \mathrm{~g}$ & & & & 0.959 \\
\hline Yes & $147(19.6)$ & $50(20)$ & $34(18.9)$ & \\
\hline No & $603(80.4)$ & $200(80)$ & $146(81.1)$ & \\
\hline 1-Minute Apgar score & & & & 0.025 \\
\hline $0-3$ & $18(2.4)$ & $12(4.8)$ & $11(6.1)$ & \\
\hline $4-6$ & $116(15.5)$ & $42(16.8)$ & $37(20.6)$ & \\
\hline$\geq 7$ & $616(82.1)$ & $196(78.4)$ & $132(73.3)$ & \\
\hline 5-Minute Apgar score & & & & $<0.001$ \\
\hline $0-3$ & $5(0.7)$ & $7(2.8)$ & $6(3.3)$ & \\
\hline $4-6$ & $12(1.6)$ & $10(4)$ & $13(7.2)$ & \\
\hline$\geq 7$ & $733(97.7)$ & $233(93.2)$ & $161(89.4)$ & \\
\hline Fetal distress & & & & $<0.001$ \\
\hline Yes & $12(1.6)$ & $11(4.4)$ & $19(10.6)$ & \\
\hline No & $738(98.4)$ & $239(95.6)$ & $161(89.4)$ & \\
\hline Meconium passage & & & & $<0.001$ \\
\hline Yes & $12(1.6)$ & $20(8)$ & $25(13.9)$ & \\
\hline No & $737(98.4)$ & $230(92)$ & $155(86.1)$ & \\
\hline Meconium aspiration & & & & $<0.001$ \\
\hline Yes & $7(0.9)$ & $14(5.6)$ & $18(10)$ & \\
\hline No & $743(99.1)$ & $236(94.4)$ & $162(90)$ & \\
\hline NICU admission & & & & $<0.001$ \\
\hline Yes & $12(1.6)$ & $10(4)$ & $12(6.66)$ & \\
\hline No & $738(98.4)$ & $240(96)$ & $168(93.34)$ & \\
\hline Cesarean section & & & & $<0.001$ \\
\hline Yes & $102(13.6)$ & $62(24.8)$ & $60(33.3)$ & \\
\hline No & $648(86.4)$ & $188(75.2)$ & $120(66.7)$ & \\
\hline Postpartum hemorrhage & & & & 0.412 \\
\hline Yes & $20(2.66)$ & $7(2.8)$ & $5(2.77)$ & \\
\hline No & $730(97.34)$ & $243(97.2)$ & $175(97.23)$ & \\
\hline Maternal infection & & & & $<0.001$ \\
\hline Yes & $25(3.33)$ & $30(12)$ & $28(15.55)$ & \\
\hline No & $725(96.67)$ & $220(88)$ & $152(84.45)$ & \\
\hline
\end{tabular}

${ }^{a}$ Values are expressed as mean \pm SD or No. (\%).

There were no significant difference in the rate of meconium aspiration syndrome, Apgar score $\leq 3$ of newborn at 1and 5 minutes, NICU admission, rate of cesarean section, maternal infection, and postpartum hemorrhage between the groups 2 and 3 (Table 4 ).

\section{Discussion}

In the current study, the rate of fetal distress, meconium passage, meconium aspiration syndrome, and required NICU admission increased after 40 weeks, com- pared with earlier weeks of gestation; there was significant differences in the rate of cesarean section and maternal infection among the 3 groups, but prenatal adverse outcomes, in group 2 with 40 to 41 weeks of gestation, such as the rate of meconium aspiration syndrome, Apgar score $\leq 3$ of newborn at 1 and 5minutes, NICU admission, and the rate of cesarean section were similar to those of group 3 with $>41$ weeks of gestation.

Some researchers suggest that induction of labor and early termination of term pregnancies had a lower incidence of meconium aspiration, low Apgar scores, postma- 
Table 2. Baseline and Demographic Characteristics in Groups 1 and 2 of the Study

\begin{tabular}{|c|c|c|c|}
\hline & $\begin{array}{l}\text { 38 - } 40 \text { Weeks of Gestation } \\
\qquad(n=750)\end{array}$ & $\begin{array}{l}40 \text { - } 41 \text { Weeks of Gestation } \\
(n=250)\end{array}$ & P Value \\
\hline Age, $y$ & $27.06 \pm 5.73$ & $27.50 \pm 5.34$ & 0.287 \\
\hline Birth weight, $\mathrm{g}$ & $3398.13 \pm 619.84$ & $3433.00 \pm 542.88$ & 0.428 \\
\hline Parity & & & 0.312 \\
\hline 1 & $382(50.9)$ & $128(51.2)$ & \\
\hline$\geq 2$ & $368(49.1)$ & $122(48.8)$ & \\
\hline Birth weight $\geq 4000 \mathrm{~g}$ & & & 0.890 \\
\hline Yes & $147(19.6)$ & $50(20)$ & \\
\hline No & $603(80.4)$ & $200(80)$ & \\
\hline 1-Minute Apgar score & & & 0.127 \\
\hline $0-3$ & $18(2.4)$ & $12(4.8)$ & \\
\hline $4-6$ & $116(15.5)$ & $42(16.8)$ & \\
\hline$\geq 7$ & $616(82.1)$ & $196(78.4)$ & \\
\hline 5-Minute Apgar score & & & 0.002 \\
\hline $0-3$ & $5(0.7)$ & $7(2.8)$ & \\
\hline $4-6$ & $12(1.6)$ & $10(4)$ & \\
\hline$\geq 7$ & $733(97.7)$ & $233(93.2)$ & \\
\hline Fetal distress & & & 0.011 \\
\hline Yes & $12(1.6)$ & $11(4.4)$ & \\
\hline No & $738(98.4)$ & 239 (95.6) & \\
\hline Meconium passage & & & $<0.001$ \\
\hline Yes & $12(1.6)$ & $20(8)$ & \\
\hline No & $738(98.4)$ & $230(92)$ & \\
\hline Meconium aspiration & & & $<0.001$ \\
\hline Yes & $7(0.9)$ & $14(5.6)$ & \\
\hline No & $743(99.1)$ & $236(94.4)$ & \\
\hline NICU admission & & & $<0.001$ \\
\hline Yes & $12(1.6)$ & $10(4)$ & \\
\hline No & $738(98.4)$ & $240(96)$ & \\
\hline Postpartum hemorrhage & & & 0.314 \\
\hline Yes & $20(2.66)$ & $7(2.8)$ & \\
\hline No & $730(97.34)$ & $243(97.2)$ & \\
\hline Maternal infection & & & $<0.001$ \\
\hline Yes & $25(3.33)$ & $30(12)$ & \\
\hline No & $725(96.67)$ & $220(88)$ & \\
\hline Cesarean section & & & $<0.001$ \\
\hline Yes & $102(13.6)$ & $62(24.8)$ & \\
\hline No & $648(86.4)$ & $188(75.2)$ & \\
\hline
\end{tabular}

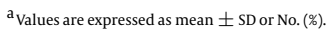

turity syndrome, and fetal distress than the patients managed with antepartum fetal testing (15-17).

Mishanina et al. presented benefits for the fetus and no increased risk of maternal death among females with induced labor than the ones with managed expectantly in term and postterm gestations (19).

The results of the current study were similar to those of the following studies.

Gulmezoglu et al. showed that the risk of prenatal mortality was lower in pregnancy termination at 41 to 42 weeks
Table 3. Baseline and Demographic Characteristics in Groups 1 and 3 of the Study ${ }^{a}$

\begin{tabular}{|c|c|c|c|}
\hline & $\begin{array}{l}38 \text { - } 40 \text { Weeks of Gestation } \\
\qquad(n=750)\end{array}$ & $\begin{array}{l}\text { Above } 41 \text { Weeks of } \\
\text { Gestation }(n=180)\end{array}$ & P Value \\
\hline Age, $y$ & $27.06 \pm 5.73$ & $27.41 \pm 5.39$ & 0.451 \\
\hline Birth weight, $\mathrm{g}$ & $3398.13 \pm 619.84$ & $3421.11 \pm 554.63$ & 0.649 \\
\hline Parity & & & 0.412 \\
\hline 1 & $382(50.9)$ & $92(51.1)$ & \\
\hline$\geq 2$ & $368(49.1)$ & $88(48.9)$ & \\
\hline Birth weight $\geq 4000 \mathrm{~g}$ & & & 0.829 \\
\hline Yes & $147(19.6)$ & $34(18.9)$ & \\
\hline No & $603(80.4)$ & $146(81.1)$ & \\
\hline 1-Minute Apgar score & & & 0.006 \\
\hline 0.3 & $18(2.4)$ & $11(6.1)$ & \\
\hline $4-6$ & $116(15.5)$ & $37(20.6)$ & \\
\hline$\geq 7$ & $616(82.1)$ & $132(73.3)$ & \\
\hline 5-Minute Apgar score & & & $<0.001$ \\
\hline $0-3$ & $5(0.7)$ & $6(3.3)$ & \\
\hline $4-6$ & $12(1.6)$ & $13(7.2)$ & \\
\hline$\geq 7$ & $733(97.7)$ & $161(89.4)$ & \\
\hline Fetal distress & & & $<0.001$ \\
\hline Yes & $12(1.6)$ & $19(10.6)$ & \\
\hline No & $738(98.4)$ & $161(89.4)$ & \\
\hline Meconium passage & & & $<0.001$ \\
\hline Yes & $12(1.6)$ & $25(13.9)$ & \\
\hline No & $738(98.4)$ & $155(86.1)$ & \\
\hline Meconium aspiration & & & $<0.001$ \\
\hline Yes & $7(0.9)$ & $18(10)$ & \\
\hline No & $743(99.1)$ & $162(90)$ & \\
\hline NICU admission & & & $<0.001$ \\
\hline Yes & $12(1.6)$ & $12(6.66)$ & \\
\hline No & $738(98.4)$ & $168(93.34)$ & \\
\hline Postpartum hemorrhage & & & 0.254 \\
\hline Yes & $20(2.66)$ & $5(2.77)$ & \\
\hline No & $730(97.34)$ & $175(97.23)$ & \\
\hline Maternal infection & & & $<0.001$ \\
\hline Yes & $25(3.33)$ & $28(15.55)$ & \\
\hline No & $725(96.67)$ & $152(84.45)$ & \\
\hline Cesarean section & & & $<0.001$ \\
\hline Yes & $102(13.6)$ & $60(33.3)$ & \\
\hline No & $648(86.4)$ & $120(66.7)$ & \\
\hline
\end{tabular}

${ }^{a}$ Values are expressed as mean $\pm S D$ or No.(\%).

of gestation than with expectant management, but did not achieve statistical significance (15). Fortunately, the current study did not have prenatal mortality.

Also, Caughey et al. suggested that females who were expectantly managed were more likely to have meconiumstained amniotic fluid than the ones who were electively induced (17). Similarly in the current study, the rate of meconium-stained amniotic fluid was higher in mothers $>40$ weeks compared with that of the ones with less than 40 weeks of gestation. 
Table 4. Baseline and Demographic Characteristics in Groups 2 and 3 of the Study ${ }^{\mathrm{a}}$

\begin{tabular}{|c|c|c|c|}
\hline & $\begin{array}{c}40-41 \text { Weeks of Gestation } \\
(n=250)\end{array}$ & $\begin{array}{l}\text { Above } 41 \text { Weeks of } \\
\text { Gestation }(n=180)\end{array}$ & P value \\
\hline Age, $y$ & $27.50 \pm 5.34$ & $27.41 \pm 5.39$ & 0.874 \\
\hline Birth weight, $\mathrm{g}$ & $3433.00 \pm 542.88$ & $3421.11 \pm 554.63$ & 0.824 \\
\hline Parity & & & 0.584 \\
\hline 1 & $128(51.2)$ & $92(51.1)$ & \\
\hline$\geq 2$ & $122(48.8)$ & $88(48.9)$ & \\
\hline Birth weight $\geq 4000 \mathrm{~g}$ & & & 0.774 \\
\hline Yes & $50(20)$ & $34(18.9)$ & \\
\hline No & $200(80)$ & $146(81.1)$ & \\
\hline 1-Minute Apgar score & & & 0.474 \\
\hline $0-3$ & $12(4.8)$ & $11(6.1)$ & \\
\hline $4-6$ & $42(16.8)$ & $37(20.6)$ & \\
\hline$\geq 7$ & $196(78.4)$ & $132(73.3)$ & \\
\hline 5-Minute Apgar score & & & 0.318 \\
\hline 0.3 & $7(2.8)$ & $6(3.3)$ & \\
\hline $4-6$ & $10(4)$ & $13(7.2)$ & \\
\hline$\geq 7$ & $233(93.2)$ & $161(89.4)$ & \\
\hline Fetal distress & & & 0.013 \\
\hline Yes & $11(4.4)$ & $19(10.6)$ & \\
\hline No & $239(95.6)$ & $161(89.4)$ & \\
\hline Meconium passage & & & 0.049 \\
\hline Yes & $20(8)$ & $25(13.9)$ & \\
\hline No & $230(92)$ & $125(86.1)$ & \\
\hline Meconium aspiration & & & 0.041 \\
\hline Yes & $14(5.6)$ & $18(10)$ & \\
\hline No & $236(94.4)$ & $162(90)$ & \\
\hline \multicolumn{4}{|l|}{ NICU admission } \\
\hline Yes & $10(4)$ & $12(6.66)$ & 0.612 \\
\hline No & $240(96)$ & $168(93.34)$ & \\
\hline Postpartum hemorrhage & & & 0.387 \\
\hline Yes & $7(2.8)$ & $5(2.77)$ & \\
\hline No & $243(97.2)$ & $175(97.23)$ & \\
\hline Maternal infection & & & 0.213 \\
\hline Yes & $30(12)$ & $28(15.55)$ & \\
\hline No & $220(88)$ & $152(84.45)$ & \\
\hline Cesarean section & & & 0.053 \\
\hline Yes & $62(24.8)$ & $60(33.3)$ & \\
\hline No & $188(75.2)$ & $120(66.7)$ & \\
\hline
\end{tabular}

${ }^{\mathrm{a}}$ Values are expressed as mean $\pm \mathrm{SD}$ or No. (\%).

But others reported induction of labor at full term in uncomplicated singleton has overall similar outcomes compared to expectant management $(14,19,20)$. In addition, meta-analysis did not find a significant difference in NICU admissions between pregnancies induced at 41 weeks of gestation and the ones with managed expectantly (15), which suggest that neonatal morbidity does not rise substantially postterm. There were significant differences in NICU admissions among the 3 groups.

Some researchers reported that the risk of cesarean de- livery was lower among females whose labor was induced than among the ones with managed expectantly in term and postterm gestations. There were benefits for the fetus, and no increased risk of maternal death. They presented that the low cesarean rate with earlier gestational age may be due to lower rates of macrosomia and abnormal intrapartum fetal heart rate tracings with earlier delivery $(14,19$, 21).

In the current study, the rate of cesarean delivery was lower before 40 weeks of gestation compared with 40 to 41 weeks and also, in 40 to 41 weeks compared with above 41 weeks; the rate of newborn with the weight $>4000 \mathrm{~g}$ was similar in the 3 groups, but the rates of fetal distress and meconium passage were significantly different among the 3 groups, and were the cause of increased cesarean section in groups 2 and 3 compared with group 1 . In the current study, the rate of fetal distress and meconium passage were similar in group 40 to 41 weeks and the group above 41 weeks; therefore, the rate of cesarean delivery was also similar between the 2 groups.

Also, some researchers reported that the rate of operative vaginal deliveries increased with delivery after 40 weeks, and the higher incidence of 3rd or 4rd degree lacerations, secondary postpartum bleeding, and prolonged labor were observed between 40 and 42 weeks, compared with before 40 weeks of gestation $(1,14,19)$.

In contrast, some studies reported no difference in the risk of cesarean delivery among females who delivered at term, compared with females who delivered late-term and postterm $(15,22)$. Thangarajah et al. reported that induction of labor in late- and postterm pregnancies was associated with a significantly higher cesarean section rate, compared with expectant management (23).

\subsection{Conclusions}

Results of the current study suggested that prenatal and maternal morbidity and the rate of cesarean sections increased after 40 weeks of gestation, compared with 38 to 40 weeks; therefore, planned early delivery is recommend versus expectant management of term and full term pregnancies.

\section{References}

1. Weiss E, Abele H, Bartz C, Franz M, Fischer T, Gembruch U, et al. S1Guideline: Management of Late-term and Post-term Pregnancy: Short version - AWMF Registry Number: 015/065. Geburtshilfe Frauenheilkd. 2014;74(12):1099-103. doi: 10.1055/s-0034-1383314. [PubMed: 27231401].

2. ACOG . ACOG Committee Opinion No 579: Definition of term pregnancy. Obstet Gynecol. 2013;122(5):1139-40. doi: 10.1097/01.AOG.0000437385.88715.4a. [PubMed: 24150030].

3. Mechurova A. . Posterm pregnancy. Ceska gynekologie/Ceska lekarska spolecnost. J Ev Purkyne. 2016;81(2):98. 
4. Elden H, Hagberg H, Wessberg A, Sengpiel V, Herbst A, Bullarbo M, et al. Study protocol of SWEPIS a Swedish multicentre register based randomised controlled trial to compare induction of labour at 41 completed gestational weeks versus expectant management and induction at 42 completed gestational weeks. BMC Pregnancy Childbirth. 2016;16:49. doi: 10.1186/s12884-016-0836-9. [PubMed: 26951777].

5. Zeitlin J, Blondel B, Alexander S, Breart G, Peristat Group . Variation in rates of postterm birth in Europe: reality or artefact?. BJOG. 2007;114(9):1097-103. doi: 10.1111/j.1471-0528.2007.01328.x. [PubMed: 17617197].

6. Feldman GB. Prospective risk of stillbirth. Obstetr Gynecol. 1992;79(4):547-53.

7. Olesen AW, Westergaard JG, Olsen J. Prenatal and maternal complications related to postterm delivery: a national register-based study, 1978-1993. Am J Obstetr Gynecol. 2003;189(1):222-7.

8. Durham N. Management of Prolonged Pregnancy. ; 2002.

9. Ehrenstein V, Pedersen L, Holsteen V, Larsen H, Rothman KJ, Sorensen HT. Postterm delivery and risk for epilepsy in childhood. Pediatrics. 2007;119(3):e554-61. doi:10.1542/peds.2006-1308. [PubMed: 17332175].

10. Moster D, Wilcox AJ, Vollset SE, Markestad T, Lie RT. Cerebral palsy among term and postterm births. JAMA. 2010;304(9):976-82. doi: 10.1001/jama.2010.1271. [PubMed: 20810375]

11. Cotzias CS, Paterson-Brown S, Fisk NM. Prospective risk of unexplained stillbirth in singleton pregnancies at term: population based analysis. BMJ. 1999;319(7205):287-8. [PubMed:10426736].

12. Joseph KS. The natural history of pregnancy: diseases of early and late gestation. BJOG. 2011;118(13):1617-29. doi: 10.1111/j.14710528.2011.03128.x. [PubMed: 21895957].

13. American College of O. Practice bulletin no.146: Management of lateterm and postterm pregnancies. Obstet Gynecol. 2014;124(2 Pt 1):3906. doi:10.1097/01.AOG.0000452744.06088.48. [PubMed: 25050770].

14. Saccone G, Berghella V. Induction of labor at full term in uncomplicated singleton gestations: a systematic review and metaanalysis of randomized controlled trials. Am J Obstet Gynecol. 2015;213(5):629-36. doi: 10.1016/j.ajog.2015.04.004. [PubMed: 25882916]
15. Gülmezoglu AM, Crowther CA, Middleton P, Heatley E, Gülmezoglu AM. Induction of labour for improving birth outcomes for women at or beyond term. The Cochrane Library; 2012.

16. Divon MY, Ferber A, Sanderson M, Nisell H, Westgren M. A functional definition of prolonged pregnancy based on daily fetal and neonatal mortality rates. Ultrasound Obstet Gynecol. 2004;23(5):423-6. doi: 10.1002/uog.1053. [PubMed: 15133787].

17. Caughey AB, Sundaram V, Kaimal AJ, Gienger A, Cheng YW, McDonald $\mathrm{KM}$, et al. Systematic review: elective induction of labor versus expectant management of pregnancy. Ann Intern Med. 2009;151(4):252-63. [PubMed: 19687492] W53-63.

18. Bond DM, Gordon A, Hyett J, de Vries B, Carberry AE, Morris J. Planned early delivery versus expectant management of the term suspected compromised baby for improving outcomes. Cochrane Database Syst Rev. 2015(11):CD009433. doi: 10.1002/14651858.CD009433.pub2. [PubMed: 26599471].

19. Mishanina E, Rogozinska E, Thatthi T, Uddin-Khan R, Khan KS, Meads C. Use of labour induction and risk of cesarean delivery: a systematic review and meta-analysis. CMAJ. 2014;186(9):665-73. doi: 10.1503/cmaj.130925. [PubMed: 24778358].

20. Caughey AB, Musci TJ. Complications of term pregnancies beyond 37 weeks of gestation. Obstet Gynecol. 2004;103(1):57-62. doi: 10.1097/01.AOG.0000109216.24211.D4. [PubMed: 14704245].

21. Bleicher I, Vitner D, Iofe A, Sagi S, Bader D, Gonen R. When should pregnancies that extended beyond term be induced?. J Matern Fetal Neonatal Med. 2017;30(2):219-23. doi: 10.3109/14767058.2016.1169520. [PubMed: 27002548].

22. Caughey AB, Stotland NE, Washington AE, Escobar GJ. Maternal and obstetric complications of pregnancy are associated with increasing gestational age at term. Am J Obstet Gynecol. 2007;196(2):155 e1-6. doi: 10.1016/j.ajog.2006.08.040. [PubMed: 17306661].

23. Thangarajah F, Scheufen P, Kirn V, Mallmann P. Induction of Labour in Late and Postterm Pregnancies and its Impact on Maternal and Neonatal Outcome. Geburtshilfe Frauenheilkd. 2016;76(7):793-8. doi: 10.1055/s-0042-107672. [PubMed: 27582577]. 